\title{
Validation of segmented and real-time EPI phase contrast flow quantification against segmented gradient echo sequences
}

\author{
Gergely V Szantho ${ }^{1 *}$, Stephen Lyen ${ }^{1}$, Chris B Lawton ${ }^{1}$, Chiara Bucciarelli-Ducci ${ }^{1}$, Nathan E Manghat ${ }^{1}$, \\ Peter J Weale ${ }^{2}$, Ning Jin², Mark Hamilton ${ }^{1}$ \\ From 18th Annual SCMR Scientific Sessions \\ Nice, France. 4-7 February 2015
}

\section{Background}

MR based Flow Quantification is an established method for measuring cardio-pulmonary haemodynamics, but is challenging to perform in situations where it may be advantageous to asses real-world physiological behavior, for example in exercise. The availability of a new real time flow quantification sequence presents the opportunity to measure velocity and flow without these challenges. This study is a preliminary validation of the method as a precursor to use of the sequence in subjects undergoing assessment of induced haemodynamic change by exercise and preload alteration.

\section{Methods}

An Echo Planar flow quantification sequence (Work In Progress package \#720 Siemens Healthcare, Erlangen, Germany) was used and validated against commercial flow quantification sequences on a $1.5 \mathrm{~T}$ MR system (Magnetom Avanto). The sequence was used in two protocols, a segmented version and a real time varient and compared to a standard product segmented protocol.

We measured ascending aortic flow with segmented EPI and RT EPI sequences in 12 and 9 healthy volunteers, respectively, and compared findings to standard flow images. The different sequences were used immediately after one another in each volunteer, during free breathing at rest.

Segmented EPI parameters: TR $17.6 \mathrm{~ms}$, TE $5.7 \mathrm{~ms}$, Voxel size $1.7 \times 2 \times 10 \mathrm{~mm}$, Flip angle $30^{\circ}$, Segments 4 .

Bristol Heart Institute, Bristol, UK

Full list of author information is available at the end of the article
RT EPI parameters: TR $61 \mathrm{~ms}$, TE $5.7 \mathrm{~ms}$, Voxel size $2.5 \times 3.2 \times 10 \mathrm{~mm}$, Flip angle $30^{\circ}$, Phases $163(=9.943 \mathrm{~s}$ to include a full breathing cycle).

Standard flow parameters: TR $29.9 \mathrm{~ms}$, TE $2.18 \mathrm{~ms}$, Voxel size $1.3 \times 1.3 \times 5 \mathrm{~mm}$, Flip angle $30^{\circ}$, Segments 3 .

Images were analyzed with commercial flow analysis software (Argus, Siemens Healthcare). RT EPI results were expressed as the mean of the beat-to-beat analysis of the actual acquisition.

We used students' paired t-test, standard deviation and Pearson's correlation coefficient for data presentation.

\section{Results}

All acquired images were evaluable. We found that stroke volume and peak flow rate measured with both segmented and RT EPI were not significantly different from standard flow measurements, showing good correlation with standard stroke volume and peak flow rate.

Segmented EPI versus standard stroke volume: $103.74+-22.02 \mathrm{ml}$ vs $105.2+-23.96 \mathrm{ml}, \mathrm{r}=0.971, \mathrm{p}<0.0001$.

RT EPI vs standard stroke volume: $97.74+-21.48 \mathrm{ml}$ vs $105.2+-23.96 \mathrm{ml}, \mathrm{r}=0.909, \mathrm{p}<0.0005$.

Segmented EPI vs standard peak flow rate: $499.08+-$ $91.66 \mathrm{ml} / \mathrm{s}$ vs $486.19+-93.11 \mathrm{ml} / \mathrm{s}, \mathrm{r}=0.935, \mathrm{p}<0.0001$

RT EPI vs standard peak flow rate: $482.16+-85.75 \mathrm{ml} / \mathrm{s}$ vs $486.19+-93.11 \mathrm{ml} / \mathrm{s}, \mathrm{r}=0.81, \mathrm{p}<0.005$.

\section{Conclusions}

Real-time and segmented EPI sequences provide reliable aortic stroke volume and peak flow rate at rest. The quick acquisition time and - in the case of the RT EPI sequence - the independency from gating make them a potential tool for detecting physiological changes during pre-load alteration and exercise. 


\section{Funding}

The WIP sequences were provided by Siemens Healthcare to our Institution for research purposes. This contract had no financial implications, and none of the parties involved (including Siemens, our Institution and the researchers) received any financial support or reward.

The time of the researchers and the scanner was funded by our Institution and the University.

There is nothing else to disclose.

\section{Authors' details}

'Bristol Heart Institute, Bristol, UK. ${ }^{2}$ Siemens Healthcare, Camberley, UK.

Published: 3 February 2015

\section{doi:10.1186/1532-429X-17-S1-066}

Cite this article as: Szantho et al:: Validation of segmented and realtime EPI phase contrast flow quantification against segmented gradient echo sequences. Journal of Cardiovascular Magnetic Resonance 2015 17(Suppl 1):066.

Submit your next manuscript to BioMed Central and take full advantage of:

- Convenient online submission

- Thorough peer review

- No space constraints or color figure charges

- Immediate publication on acceptance

- Inclusion in PubMed, CAS, Scopus and Google Scholar

- Research which is freely available for redistribution

Submit your manuscript at www.biomedcentral.com/submit
C Biomed Central 